\title{
Establishment and Evaluation of a Loop-Mediated Isothermal Amplification Assay for Detection of Raccoon Dog in Meat Mixtures
}

\author{
Jinhua Liu, ${ }^{1,2}$ Yanyu Shi, ${ }^{3}$ Siying Teng, ${ }^{4}$ Lianpeng $\mathrm{Wu},{ }^{2}$ and Xinmin $\mathrm{Zhang}^{1}$ \\ ${ }^{1}$ School of Pharmaceutical Sciences, Jilin University, Changchun, Jilin, China \\ ${ }^{2}$ Jilin Entry-Exit Inspection and Quarantine Bureau, Changchun, Jilin, China \\ ${ }^{3}$ Jilin Product Quality Supervision Inspection, Changchun, Jilin, China \\ ${ }^{4}$ Department of Ophthalmology, First Hospital of Jilin University, Changchun, Jilin, China \\ Correspondence should be addressed to Xinmin Zhang; zhangxinmin@jlu.edu.cn
}

Received 23 August 2016; Revised 21 November 2016; Accepted 19 December 2016; Published 10 January 2017

Academic Editor: Alejandro Hernández

Copyright (C) 2017 Jinhua Liu et al. This is an open access article distributed under the Creative Commons Attribution License, which permits unrestricted use, distribution, and reproduction in any medium, provided the original work is properly cited.

Raccoon dog (Nyctereutes procyonoides) is an economically important animal used for fur production, but consuming its meat is injurious to human health. Currently, no rapid and sensitive method for detecting raccoon dog meat in meat mixtures is available. In this study, we developed an easily applicable, rapid, and economically feasible method for identifying the presence of raccoon dog in meat mixtures based on loop-mediated isothermal amplification (LAMP). Four sets of LAMP primers were tested at different temperatures, and the primers that worked best at $62^{\circ} \mathrm{C}$ (set 2) were determined. In the LAMP assay, there was no cross-reactivity with the meat procured from other species of animals and the detection limit of DNA concentration was $0.1 \mathrm{pg} \cdot \mu \mathrm{L}^{-1}$, slightly higher than TaqMan real-time PCR $\left(0.01 \mathrm{pg} \cdot \mu \mathrm{L}^{-1}\right)$, but sensitivity of $0.1 \mathrm{pg} \cdot \mu \mathrm{L}^{-1}$ complies with most requirements of routine analysis. Moreover, by the LAMP method, the meat mixtures containing more than $0.5 \%$ of the raccoon dog component were directly detected (without DNA extraction) in the supernatant isolated from the meat mixtures after performing repeated cycles of thawing and freezing of minced meat mixtures. Our results show that LAMP assay is a valuable, straightforward, and sensitive detection tool for identification of raccoon dog meat in mixtures.

\section{Introduction}

Raccoon dog is a member of the canid family; its fur is an economically important product. Wild and domesticated raccoon dogs are widely distributed in Asia [1], North America, and Europe [2]. The felt made from the fur of raccoon dogs is a highly expensive object in the commercial market; however, raccoon dog meat is much cheaper than other kinds of meat due to its unpleasant taste and poor texture. Furthermore, when it is included in the composition of meat mixtures, especially in dressed meat, its appearance and taste resemble the meat obtained from other animals. Thus, raccoon dog meat is often included as a subsidiary component in compound meat mixtures that are primarily made from mutton, beef, pork, and so forth. People consume raccoon dog meat unknowingly since this compound meat mixture is often labeled as mutton, beef, pork, and so forth. In some cases, consumers' health gets deteriorated. Presently, there is no standard method through which raccoon dog meat can be identified in mixtures. Therefore, the development of a specific, accurate, and feasible technique through which raccoon dog meat can be detected is urgent. The identification of the species origin of meat is performed primarily through the standards of sensory evaluation and determination of proteins and oligonucleotides [3-5]. However, the histological and morphologic characteristics or speciesspecific epitopes might be altered or destroyed during meat processing and cooking. Therefore, it is extremely difficult to precisely identify the composition of meat by sensory analysis or protein-based assays, such as SDS-PAGE, Western blotting, and enzyme-linked immunosorbent assay (ELISA). In addition, most of the protein-based detection methods also 
have disadvantages, such as low specificity, complexity, and high cost. The DNA molecule is relatively stable and is able to withstand extreme heat and pressure, which are applied during the processing of meat. The species origin of meat can be determined through numerous nuclear DNA-based methods available such as DNA hybridization, polymerase chain reaction (PCR) [6], loop-mediated isothermal amplification (LAMP) [7], and sequencing. However, most of these methods require the availability of specialized equipment and professionally trained personnel. Hence, they are not suitable for carrying out routine food inspection and cannot be used for monitoring samples on a daily basis.

LAMP assay is a fast, economic, specific, and sensitive method originally developed by Notomi et al. [8]. In LAMP, the strand-displacement activity of Bst polymerase to amplify DNA under isothermal conditions is utilized. Thus, the reaction can be performed in a simple incubator, such as a heating metal block or water bath. Furthermore, Bst polymerase tolerates impurities to a certain extent, causing the amplification of relatively crude samples; Bst polymerase exhibits its activity even when the DNA is not in its highly purified form [9]. Moreover, the amplification products can easily be detected by turbidity, fluorescence, or gel electrophoresis.

In the present study, a LAMP method for identifying raccoon dog meat was developed and validated. Four sets of primers were designed using the mitochondrial DNA (GenBank Accession numbers NC_013700), of which the optimal one was selected. A range of reaction temperatures $\left(50-65^{\circ} \mathrm{C}\right)$ were investigated to determine the most favorable temperature for amplification, and $62^{\circ} \mathrm{C}$ was found to be the optimal temperature. It is noteworthy that the sensitivity of this assay was similar to that of qPCR. In addition, through the use of the LAMP assay, the raccoon dog component could be directly detected from the supernatant after performing repeated cycles of freezing and heating of minced meat without DNA purification. Our results suggest that this easily applicable assay is economically feasible and highly efficient method for identification of raccoon dog meat in meat mixtures or other inappropriately labeled meat products.

\section{Materials and Methods}

2.1. Sample Collection and Preparation. Raccoon dog muscle was obtained from an animal breeding farm in Jiutai of China. Meat samples of pig (Sus scrofa), cattle (Bos taurus), deer (Cervus elaphus), dog (Canis lupus), horse (Equus caballus), sheep (Ovis aries), and rabbit (Oryctolagus cuniculus) were purchased from local market suppliers in Changchun, Jilin, China. All samples were stored at $-20^{\circ} \mathrm{C}$ until DNA extraction.

2.2. DNA Extraction. Total DNA, including genomic DNA and mitochondrial DNA (mtDNA), was extracted from raw, processed raccoon dog meat or meat mixtures using an improved CTAB method [10]. Briefly, tissue was finely minced with a scalpel blade. Then, a quantity of $0.5 \mathrm{~g}$ of the minced meat was measured and incubated at $65^{\circ} \mathrm{C}$ in $2 \mathrm{~mL}$
CTAB buffer ( $2 \%$ w/v CTAB, $1.42 \mathrm{M} \mathrm{NaCl}, 20 \mathrm{mM}$ EDTA, and $100 \mathrm{mM}$ Tris- $\mathrm{HCl}$ with $\mathrm{pH}$ 8.0) in a microcentrifuge tube containing $50 \mu \mathrm{L}$ of $0.1 \mathrm{mg} \cdot \mu \mathrm{L}^{-1}$ proteinase $\mathrm{K}$ (Sigma) and $4 \mu \mathrm{L}$ of $\beta$-mercaptoethanol (added just before use). Three hours later, the samples were cooled briefly, and $400 \mu \mathrm{L}$ of the supernatant was used for DNA purification conducted by phenol-chloroform-isoamyl $(25: 24: 1)$ extraction, followed by a single isopropanol precipitation. The extracted DNA was stored at $-20^{\circ} \mathrm{C}$. DNA was quantified by BioSpectrometer at $260 \mathrm{~nm}$ (Eppendorf, Germany). DNA concentration was adjusted to $100 \mathrm{ng} \cdot \mu \mathrm{L}^{-1}$ for subsequent PCR reactions.

2.3. Design of Primers and Probe. Sequences of mtDNA of raccoon dog, cattle, deer, dog, horse, pig, sheep, and rabbit, which were obtained from GenBank with accession numbers NC_013700, NC_006853.1, NC_007704, NC_002008, X79547.1, AP003428.1, AF010406.1, and NC_001913 were aligned. Mismatch areas were identified by software DNAMAN. The CYTB gene was chosen to generate LAMP primers. The LAMP method required the utilization of four sets of primers, two outer (F3 and B3) and two inner (forward inner primer (FIP) and reverse inner primer (BIP)) primers, which recognized six distinct regions of the target sequence (F1, F2, F3, B1, B2, and B3). The primers were designed using the online software Primer Explorer (http://primerexplorer.jp/elamp4.0.0/index.html, Eiken Chemical Co., Ltd., Japan).

TaqMan real-time PCR primers and probe were designed for raccoon dog using the D-lopp region of mitochondrial DNA (GenBank Accession numbers NC_013700) through Primer 5 software. All primers and the TaqMan probe (presented in Table 1) were synthesized by Sangon Biotech (Shanghai, China).

2.4. LAMP Reaction and Amplification Conditions. The LAMP reaction was performed with a Loopamp ${ }^{\circledR}$ DNA Amplification kit (Lanpu Biotech, Beijing, China). The amount of reaction components was added according to the instructions of the kit. The optimal reaction condition was evaluated by using different amplification temperatures $\left(60^{\circ} \mathrm{C}-65^{\circ} \mathrm{C}\right)$ for $60 \mathrm{~min}$, and the amplified products were judged by color change.

2.5. TaqMan Real-Time PCR Reaction and Amplification Conditions. TaqMan real-time PCR reactions were performed in a total volume of $20 \mu \mathrm{L}$ in a MicroAmp ${ }^{\circledR}$ Fast 8 -Tube Strip (Applied Biosystems), covered with MicroAmp ${ }^{\circledR}$ Optical 8Cap Strip (Applied Biosystems). Each reaction mixture contained $1 \mu \mathrm{L}$ of DNA, $10 \mu \mathrm{L}$ of TaqMan ${ }^{\circledR}$ Environmental Master Mix 2.0, a final concentration of $400 \mathrm{nM}$ for each primer, and $200 \mathrm{nM}$ for the probe. TaqMan reactions were run on StepOnePlus ${ }^{\mathrm{TM}}$ (Applied Biosystems) with the following thermal cycling protocol: $95^{\circ} \mathrm{C}$ for $10 \mathrm{~min}$, followed by 40 or 45 cycles of $95^{\circ} \mathrm{C}$ for $15 \mathrm{~s}$, and $60^{\circ} \mathrm{C}$ for $1 \mathrm{~min}$.

2.6. Sensitivity and Specificity of LAMP Assay. The detection limits of the LAMP assay and TaqMan real-time PCR were determined by the limiting dilution method. The amount of 
TABLE 1: LAMP primers used in this study.

\begin{tabular}{lc}
\hline Primer name & Nucleotide sequence $\left(5^{\prime} \rightarrow 3^{\prime}\right)$ \\
\hline Set 1-F3 & GTTACGTGTTACCCTGAGG \\
Set 1-B3 & AATGAATGGGAGGATGAAGT \\
Set 1-FIP & CAATGTATGGGATGGCGGAAAG-ACAAATGTCATTCTGAGGAGC \\
Set 1-BIP & TTGGTTGAGTGAATTTGAGGAGG-GGAATGCGAAAAATCGTGT \\
Set 2-F3 & TAACCTCCTTTCCGCCAT \\
Set 2-B3 & GAGGGATTATTGGATCCGG \\
Set 2-FIP & AGGTTGCCTTGTCTACTGAGAA-ATACATTGGAACTAATTTGGTTGAG \\
Set 2-BIP & ACACGATTTTTCGCATTCCACT-TTCGTGGAGGAACAGAAGA \\
Set 3-F3 & CGAGGCCTATACTATGGATC \\
Set 3-B3 & CTCCTCAAATTCACTCAACC \\
Set 3-FIP & CCTATGAATGCCGTAGCTATGGTC-TTCATAGAAACATGGAACATCG \\
Set 3-BIP & TGTTACCCTGAGGACAAATGTCA-ATTAGTTCCAATGTATGGGATG \\
Set 4-F3 & TATTGATCTCCCCGCACC \\
Set 4-B3 & GCGTGTATATAGCGGATGA \\
Set 4-FIP & AGTGTATGGCTAGAAATAGACCTGT-ATCTCTGCCTGATGAAACT \\
Set 4-BIP & ACATCAGATACCTCTACTGCCTT-GCCGTAATTGACGTCTCG \\
TaqMan forward primer & CTATACCTGGCATCTGGTTCTTACC \\
TaqMan reverse primer & GTCCCATTTGAGTGGATTAGTAGGA \\
TaqMan probe & FAM-CAGGGCCATGAACTCCCTCCATCC-TAMRA \\
\hline
\end{tabular}

DNA was estimated by BioSpectrometer (Eppendorf, Germany). Serially tenfold-diluted purified raccoon dog DNA (from $1 \mathrm{fg}$ to $100 \mathrm{ng}$ ) was used as a template to determine the detection limit. The specificity of this assay was tested by amplifying the DNA samples of raccoon dog, cattle, deer, dog, horse, pig, sheep, and rabbit as templates to detect any nonspecific amplification.

2.7. Direct Testing of Meat Samples. Mixtures of bovine meat were prepared with $50 \%, 10 \%, 5 \%, 1 \%, 0.5 \%$, and $0.1 \%$ of raccoon dog meat. Each mixture was minced, mixed with equal volume of $20 \mathrm{mM}$ Tris-HCl EDTA ( $\mathrm{pH}$ 8.0) using a blender (Waring Commercial, USA). Further, the samples were repeatedly (three times) frozen at $-20^{\circ} \mathrm{C}$ for approximately $1 \mathrm{~h}$ and heated at $50^{\circ} \mathrm{C}$ for $30 \mathrm{~min}$. Finally, they were spun down, and $1 \mu \mathrm{L}$ of the supernatant was used to perform the LAMP and TaqMan real-time PCR assay.

\section{Results}

3.1. Optimal Reaction Condition and Primers of LAMP Assay. Using approximately $25 \mathrm{ng}$ DNA of raccoon dog, four sets of primers were tested under isothermal conditions (from $60^{\circ} \mathrm{C}$ to $65^{\circ} \mathrm{C}$ ) for $60 \mathrm{~min}$. Among those four sets of primers, optimal results were achieved in primer set 2 ; the color of their products was greener than that of the others, especially at $62^{\circ} \mathrm{C}$. The action of the primers of set 3 was unsatisfactory (Figure 1). Therefore, the optimized primers of set 2 were used for the rest of experiments at $62^{\circ} \mathrm{C}$ for $60 \mathrm{~min}$.

To obtain the reaction curve with the lowest $\mathrm{Ct}$ value and the highest final fluorescence, the primer and probe concentrations were optimized. The concentrations of 200, 400 , and $600 \mathrm{nM}$ for the primers and 200 and $300 \mathrm{nM}$ for the probe were tested. Finally, an optimal concentration of $400 \mathrm{nM}$ for the primers and $200 \mathrm{nM}$ for the probe was selected (Figure 2).

3.2. Specificity of LAMP Assay. The specificity of LAMP assay was tested by amplifying the DNA samples of raccoon dog, cattle, deer, dog, horse, pig, sheep, and rabbit. As expected, no significant amplification was detected in the samples of the above-mentioned seven species except for that of raccoon dog using both assays (Figures 3 and 4). The results indicated that LAMP and TaqMan real-time PCR assays were specific for raccoon dog identification.

3.3. Limits of LAMP Assay. The limit of detection of the assay was determined using 10-fold dilutions of raccoon dog DNA diluted in $\mathrm{ddH}_{2} \mathrm{O}$. The results showed that LAMP assay can detect a DNA concentration as low as $0.1 \mathrm{pg} \cdot \mu \mathrm{L}^{-1}$ (Figure 5), and the TaqMan real-time PCR assay can detect a DNA concentration as low as $0.01 \mathrm{pg} \cdot \mu \mathrm{L}^{-1}$ (Figure 6).

3.4. Direct Meat Sample Testing. The LAMP assay results indicated that as low as $0.5 \%$ of raccoon dog component could be directly detected from meat samples (Figure 7), and some of the samples contained even lower quantities $(0.1 \%)$. However, the TaqMan PCR assay results showed that no correlation existed between the amplifications and the changes in the content of raccoon dog component (Figure 8).

\section{Discussion}

Raccoon dog, a predominantly domesticated animal, is economically important. However, the animal's tissue can 


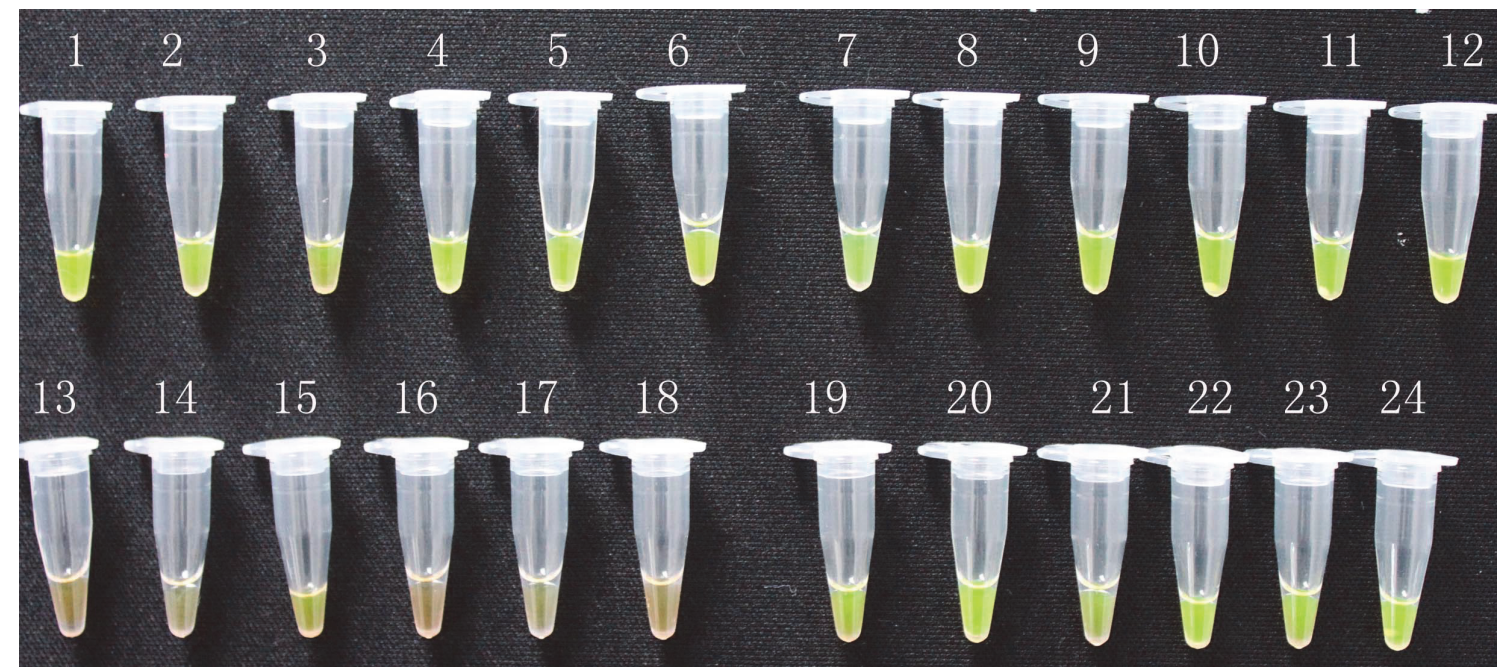

FIgURE 1: Optimal reaction condition and primers used in the LAMP assay. Amplified products were judged by color change. A positive reaction was indicated by a color change from orange to green. Tubes: $1-6$, primers set $1\left(60^{\circ} \mathrm{C}-65^{\circ} \mathrm{C}\right) ; 7-12$, primers set $2\left(60^{\circ} \mathrm{C}-65^{\circ} \mathrm{C}\right) ; 13-18$, primers set $3\left(60^{\circ} \mathrm{C}-65^{\circ} \mathrm{C}\right) ; 19-24$, primers set $4\left(60^{\circ} \mathrm{C}-65^{\circ} \mathrm{C}\right)$. The color of the primers of set 2 was greener than that of the others, especially at $62^{\circ} \mathrm{C}$.

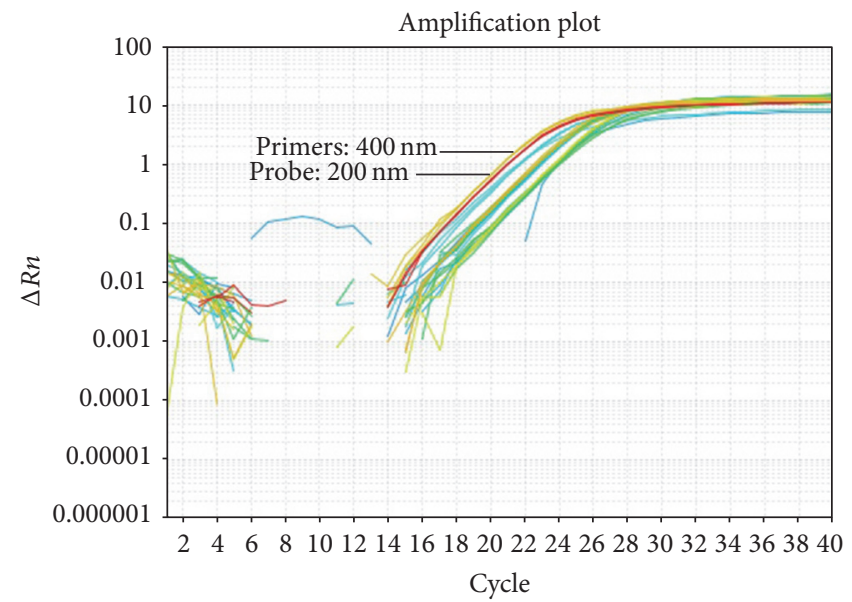

FIgure 2: Optimal primers and probe used in the TaqMan real-time PCR.

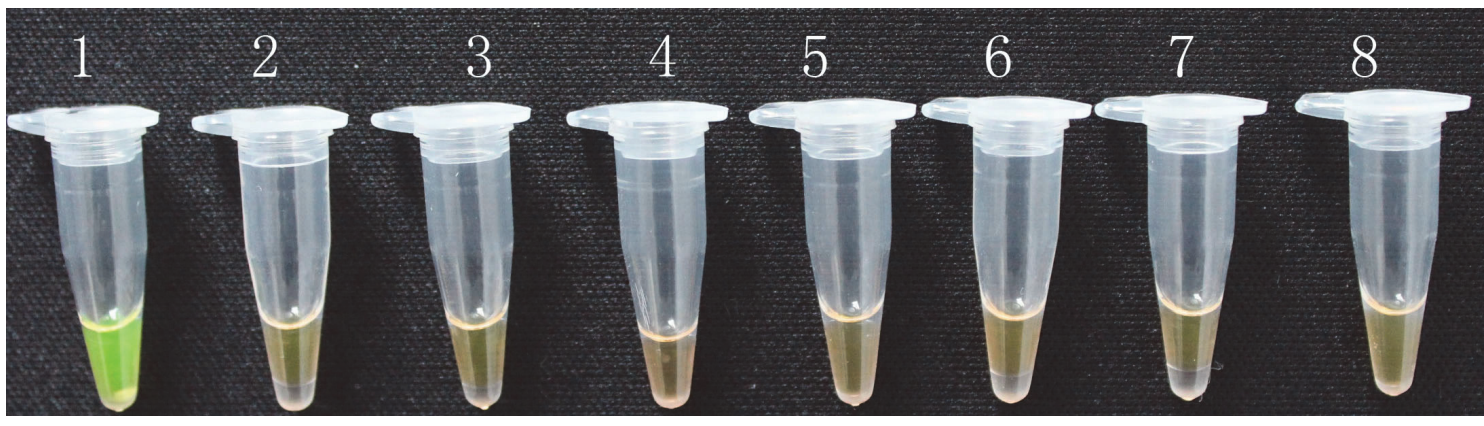

Figure 3: Specificity of LAMP assay. Tubes: 1 , raccoon dog; 2, cattle; 3, deer; 4, dog; 5 , horse; 6 , pig; 7, sheep; 8 , rabbit. The color of raccoon dog samples turned green, whereas the color of the others was still orange. 


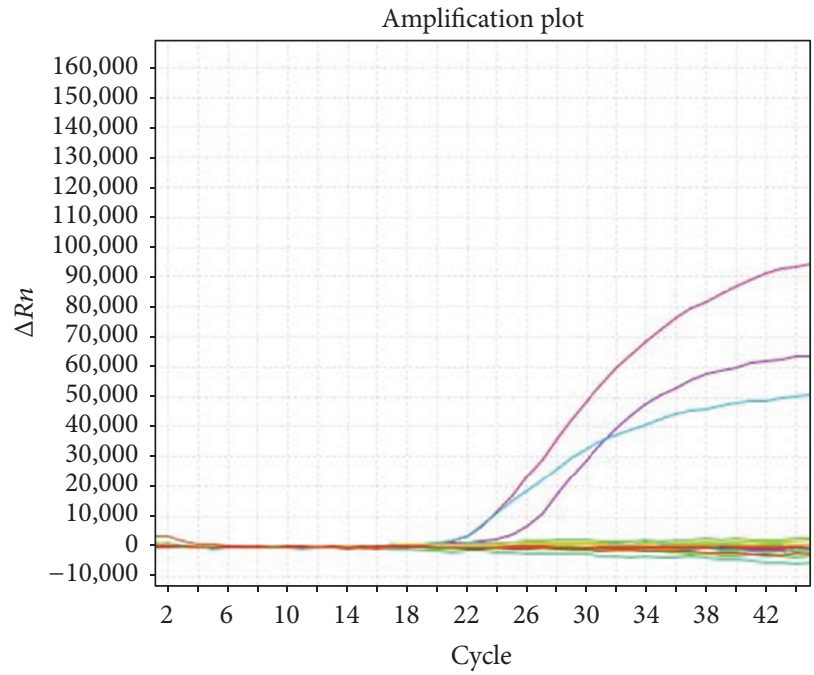

Figure 4: Species-specificity assay for raccoon dog identification. Raccoon dog samples gave positive results. No cross-reactivity with cattle, deer, dog, horse, pig, sheep, and rabbit was detected.

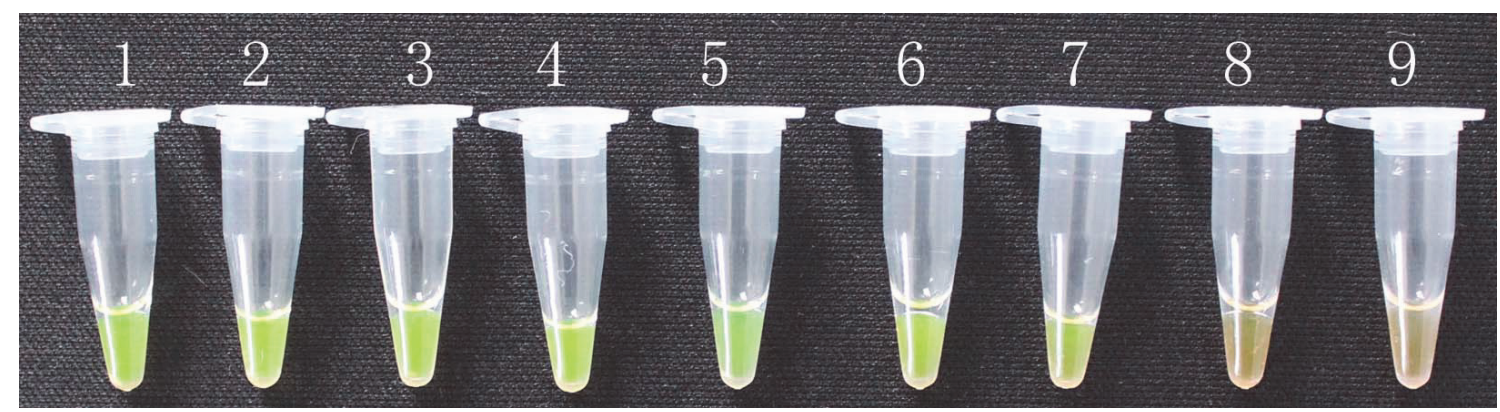

FIGURE 5: Limit of detection of LAMP assay. Tubes 1-9: nine 10-fold dilutions of purified DNA with concentrations ranging from 1 fg to $100 \mathrm{ng}$ per microliter (tubes 1 to 9 in order) were tested. The limit of detection of LAMP assay was $0.1 \mathrm{pg} \cdot \mu \mathrm{L}^{-1}$.

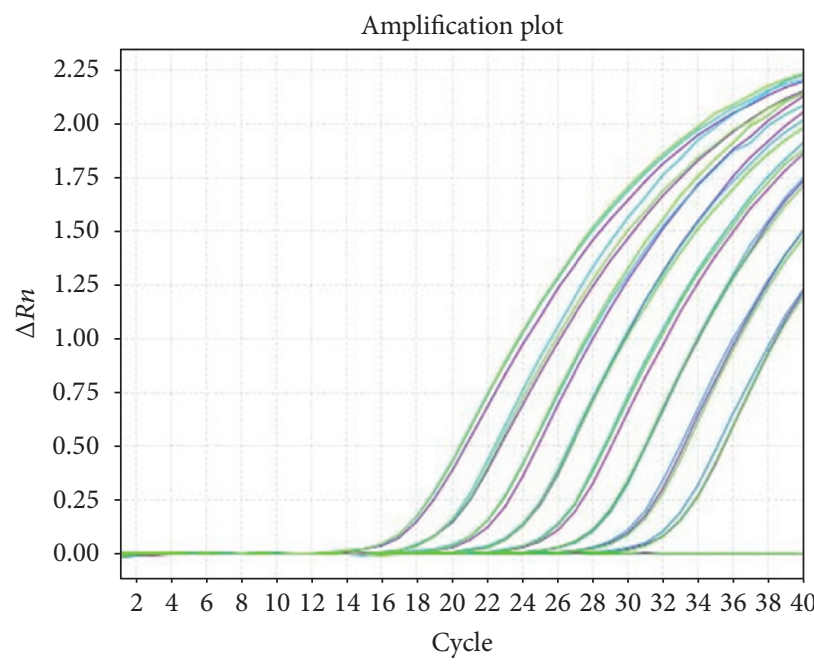

FIGURE 6: Limit of TaqMan PCR assay for raccoon dog detection. Nine 10-fold dilutions of purified DNA that concentration ranged from 1 fg to $100 \mathrm{ng}$ per microliter were tested. The reactions were performed in triplicate. The limit of detection of the PCR assay was $0.01 \mathrm{pg} \cdot \mu \mathrm{L}^{-1}$. 


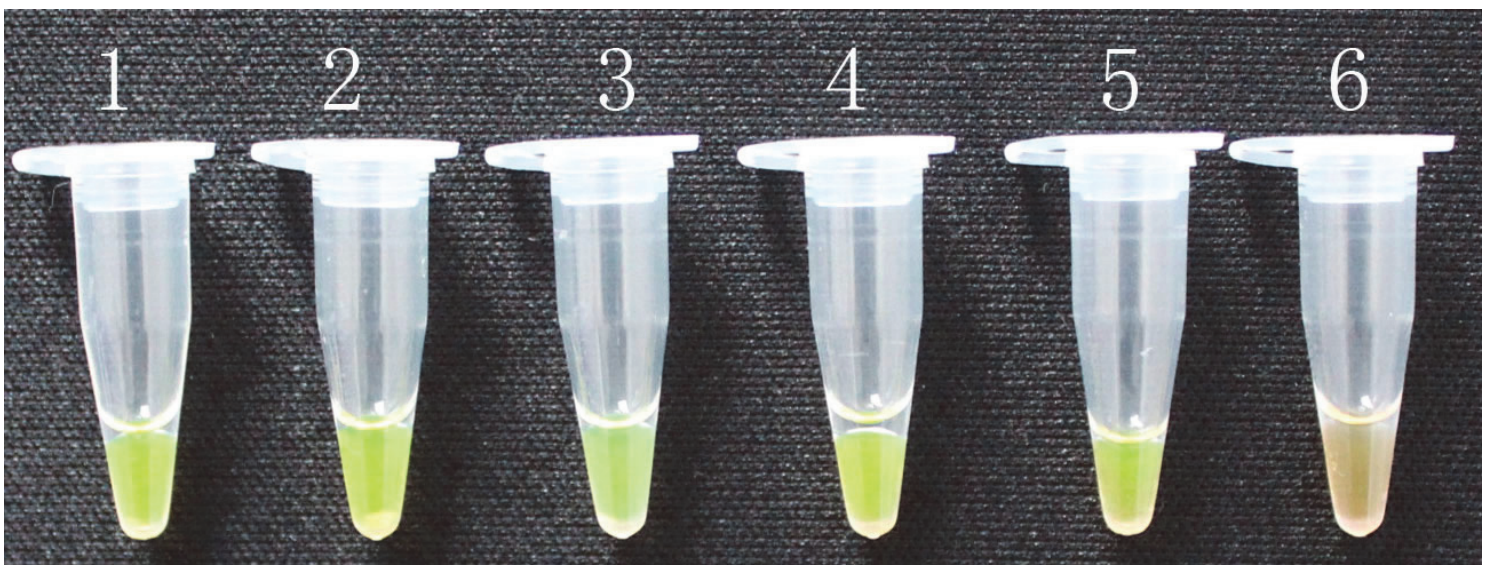

FIGURE 7: Direct testing of meat samples using LAMP assay. Tubes 1-6: meat mixtures of bovine meat were prepared with 50\%, 10\%, 5\%, $1 \%, 0.5 \%$, and $0.1 \%$ of raccoon dog meat, respectively. Amounts of raccoon dog component higher than $0.5 \%$ of the mixture were directly detected.

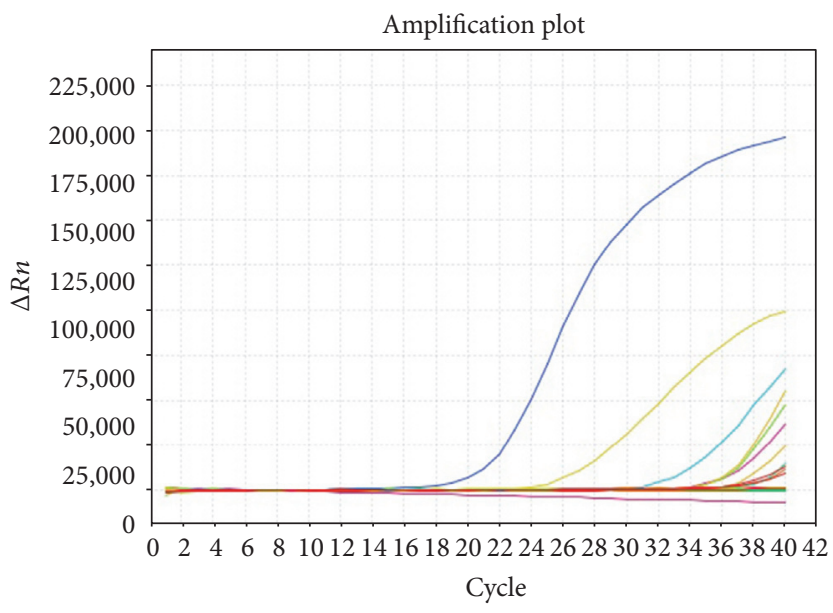

FIGURE 8: Direct testing of meat samples using TaqMan PCR assay.

be a host to several different pathogens, such as parasitic worms [11], rabies virus [12], SARS-coronavirus [13], avian influenza A viruses [14], tuberculosis [15], and mycoplasma [16]. Therefore, the consumption of raccoon dog meat may be hazardous or even life-threatening to human health. Most of the studies conducted on the detection of species origin of meat have been performed in common domesticated economic animals, such as pig [17], cow [18], sheep [19], and chicken [20]. Thus, in this study, our primary purpose was to develop a novel method for detection of raccoon dog meat through which different content of raccoon dog meat in meat mixtures can be determined. Our findings will contribute to the protection of consumers' right and health from the harm or danger caused by the consumption of this food.

In some cases, exceedingly small amounts of raccoon dog meat are mixed with meat of other species. However, it is difficult to detect this intentional or unintentional adulteration in meat mixtures. Each species has a specific circular molecule of mitochondrial DNA that is present in every type of its cells and tissues. The most important feature of mtDNA is that it can be found in higher numbers in cells compared to that of nuclear DNA. Therefore, using mtDNA as a target would allow much easier amplification even if the raccoon dog meat component is present in the lowest concentration among other types of meat in a meat mixture $[21,22]$. Therefore, to increase sensitivity of detection, in our study, mtDNA was chosen as a target sequence. The results showed that as low as $0.1 \mathrm{pg} \cdot \mu \mathrm{L}^{-1}$ of DNA, or higher than $1 \%$ component in a meat mixture, can be detected by LAMP assay, which is sufficient sensitivity for conducting most routine detection tasks.

A successful and suitable LAMP assay result is not only determined by DNA amplification efficiency; the method selected for monitoring the reaction product is equally important, and many detection methods have been developed $[23,24]$. The final reaction product can be directly observed by the reaction of magnesium pyrophosphate precipitation [25], the color change which is caused by DNAbinding dyes [26] and indirect colorimetric indicators [27], or the special band at the test line on the strip using lateral 
flow dipstick (LFD) assay [28], and the LAMP products are also analyzed by gel electrophoresis at the endpoint [29]. The real-time LAMP reaction can be monitored by a turbidity meter or a real-time fluorescence detector [30]. The aim of our investigation was to develop an economical, sensitive, and rapid method to detect raccoon dog ingredients in a meat mixture. Nevertheless, real-time assays and electrophoresis analysis require the utilization of additional, costly detection equipment. The LFD assay is a specific and sensitive method that does not require any specialized instrumentation. However, a FITC-labeled DNA probe and a biotin-labeled outer primer have to be synthetized; furthermore, the strip is also expensive, making this assay costly to perform routinely. The color changes obtained by using a DNA-binding dye or a colorimetric indicator are much easier to observe than those of magnesium pyrophosphate precipitation. Nevertheless, the reaction tube has to be open to add the DNA-binding dye, whereas the colorimetric indicator can be directly added to the reaction mixture at the beginning. Therefore, for easier observations of the color change than turbidness and manipulations in our study, the LAMP kit including the colorimetric indicator calcein was utilized, and the colorimetric indicator was directly added before the reaction started. Unlike in the DNA-binding dye real-time reaction, there was no need to open the tube. The reason for the color changes from orange to green was that the fluorescence of calcein was quenched due to the binding of calcein to the manganese ion. Calcein molecules released manganous ions competitive binding to the newly generated pyrophosphate ions from the LAMP reaction, thereby recovering its green fluorescence.

To find a much cheaper, faster, and more feasible method to identify raccoon dog component in meat mixtures, we compared the LAMP assay and TaqMan real-time PCR assay. Our results suggest that LAMP assay has the same specificity as TaqMan real-time PCR assay but is with a slightly lower sensitivity. Nevertheless, the LAMP assay performed well in the direct testing of meat samples, whereas TaqMan real-time PCR assay did not work well. TaqMan real-time PCR assay is one the most popular molecular methods for detection of the origin of meat species $[31,32]$ but requires a dedicated real-time PCR machine, which is exceedingly expensive and not yet widely available. Thus, LAMP assay might be an adequate option in a basic detection station in developing countries.

\section{Conclusions}

Considering its high specificity, sensitivity, and applicability, the developed LAMP assay described in this study is both reliable and suitable for detection of raccoon dog ingredients in food samples.

\section{Additional Points}

Practical Applications. LAMP assay may be used in the meat industry as a fast and straightforward tool for identification of raccoon dog from meat mixture.

\section{Competing Interests}

The authors declare that there are no competing interests regarding the publication of this paper. The National Natural Science Foundation of China does not have any conflict of interests regarding the publication of this manuscript.

\section{Acknowledgments}

This study was supported by the National Natural Science Foundation of China (Grant no. 31200953).

\section{References}

[1] W. Nie, J. Wang, P. Perelman, A. S. Graphodatsky, and F. Yang, "Comparative chromosome painting defines the karyotypic relationships among the domestic dog, Chinese raccoon dog and Japanese raccoon dog," Chromosome Research, vol. 11, no. 8, pp. 735-740, 2003.

[2] A. Sutor, S. Schwarz, and F. J. Conraths, "The raccoon dog (Nyctereutes procyonoides) in Germany-an established Neozoon as host and vector for parasites and other pathogenes," Berliner und Munchener Tierarztliche Wochenschrift, vol. 124, no. 11-12, pp. 457-464, 2011.

[3] A. Macedo-Silva, S. F. C. Barbosa, M. G. A. Alkmin, A. J. Vaz, M. Shimokomaki, and A. Tenuta-Filho, "Hamburger meat identification by dot-ELISA," Meat Science, vol. 56, no. 2, pp. 189-192, 2000.

[4] E. Sakalar, S. Ö. Ergün, and E. Akar, "A simultaneous analytical method for duplex identification of porcine and horse in the meat products by EvaGreen based real-time PCR," Korean Journal for Food Science of Animal Resources, vol. 35, no. 3, pp. 382-388, 2015.

[5] C. Floren, I. Wiedemann, B. Brenig, E. Schütz, and J. Beck, "Species identification and quantification in meat and meat products using droplet digital PCR (ddPCR)," Food Chemistry, vol. 173, pp. 1054-1058, 2015.

[6] T. Kitpipit, K. Sittichan, and P. Thanakiatkrai, "Direct-multiplex PCR assay for meat species identification in food products," Food Chemistry, vol. 163, pp. 77-82, 2014.

[7] M. S. Draz and X. Lu, "Development of a Loop Mediated Isothermal Amplification (LAMP) - Surface Enhanced Raman spectroscopy (SERS) assay for the detection of Salmonella enterica serotype enteritidis," Theranostics, vol. 6, no. 4, pp. 522$532,2016$.

[8] T. Notomi, H. Okayama, H. Masubuchi et al., "Loop-mediated isothermal amplification of DNA," Nucleic acids research, vol. 28, no. 12, article no. e63, 2000.

[9] P. Kogovšek, J. Hodgetts, J. Hall et al., "LAMP assay and rapid sample preparation method for on-site detection of flavescence dorée phytoplasma in grapevine," Plant Pathology, vol. 64, no. 2, pp. 286-296, 2015.

[10] C. N. Stewart Jr. and L. E. Via, "A rapid CTAB DNA isolation technique useful for RAPD fingerprinting and other PCR applications," BioTechniques, vol. 14, no. 5, pp. 748-750, 1993.

[11] H. Sato, T. Inaba, Y. Ihama, and H. Kamiya, "Parasitological survey on wild carnivora in north-western Tohoku, Japan," Journal of Veterinary Medical Science, vol. 61, no. 9, pp. 10231026, 1999.

[12] J.-K. Oem, S.-H. Kim, Y.-H. Kim, M.-H. Lee, and K.-K. Lee, "Complete genome sequences of three rabies viruses isolated 
from rabid raccoon dogs and a cow in Korea," Virus Genes, vol. 47, no. 3, pp. 563-568, 2013.

[13] P. K. S. Chan and M. C. W. Chan, "Tracing the SARS-coronavirus," Journal of Thoracic Disease, vol. 5, supplement 2, pp. S118S121, 2013.

[14] X. Qi, X. Li, P. Rider et al., "Molecular characterization of highly pathogenic $\mathrm{H} 5 \mathrm{~N} 1$ avian influenza a viruses isolated from raccoon dogs in China," PLoS ONE, vol. 4, no. 3, Article ID e4682, 2009.

[15] W. Frank, E. C. Reisinger, W. Brandt-Hamerla, I. Schwede, and W. Handrick, "Mycobacterium microti-pulmonary tuberculosis in an immunocompetent patient," Wiener Klinische Wochenschrift, vol. 121, no. 7-8, pp. 282-286, 2009.

[16] R. Harasawa, R. Orusa, and M. Giangaspero, "Molecular evidence for hemotropic mycoplasma infection in a Japanese badger (Meles meles anakuma) and a raccoon dog (Nyctereutes procyonoides viverrinus)," Journal of Wildlife Diseases, vol. 50, no. 2, pp. 412-415, 2014.

[17] G. Chen, Y. Sui, and S. Chen, "Detection of flavor compounds in longissimus muscle from four hybrid pig breeds of Sus scrofa, Bamei pig, and Large White," Bioscience, Biotechnology and Biochemistry, vol. 78, no. 11, pp. 1910-1916, 2014.

[18] D. K. Trivedi, K. A. Hollywood, N. J. W. Rattray et al., "Meat, the metabolites: an integrated metabolite profiling and lipidomics approach for the detection of the adulteration of beef with pork," Analyst, vol. 141, no. 7, pp. 2155-2164, 2016.

[19] P. P. Makwana, J. B. Nayak, M. N. Brahmbhatt, and J. H. Chaudhary, "Detection of Salmonella spp. from chevon, mutton and its environment in retail meat shops in Anand city (Gujarat), India," Veterinary World, vol. 8, no. 3, pp. 388-392, 2015.

[20] B. Hou, X. Meng, L. Zhang, J. Guo, S. Li, and H. Jin, "Development of a sensitive and specific multiplex PCR method for the simultaneous detection of chicken, duck and goose DNA in meat products," Meat Science, vol. 101, pp. 90-94, 2015.

[21] I. Martín, T. García, V. Fajardo et al., "Mitochondrial markers for the detection of four duck species and the specific identification of Muscovy duck in meat mixtures using the polymerase chain reaction," Meat Science, vol. 76, no. 4, pp. 721-729, 2007.

[22] A. M. G. Galan, M. Brohée, E. De Andrade Silva, A. J. Van Hengel, and H. Chassaigne, "Development of a real-time PCR method for the simultaneous detection of soya and lupin mitochondrial DNA as markers for the presence of allergens in processed food," Food Chemistry, vol. 127, no. 2, pp. 834-841, 2011.

[23] X. Zhang, S. B. Lowe, and J. J. Gooding, "Brief review of monitoring methods for loop-mediated isothermal amplification (LAMP)," Biosensors and Bioelectronics, vol. 61, pp. 491-499, 2014.

[24] T. Notomi, Y. Mori, N. Tomita, and H. Kanda, "Loop-mediated isothermal amplification (LAMP): principle, features, and future prospects," Journal of Microbiology, vol. 53, no. 1, pp. 15, 2015.

[25] R. Kubota, B. G. Vine, A. M. Alvarez, and D. M. Jenkins, "Detection of Ralstonia solanacearum by loop-mediated isothermal amplification," Phytopathology, vol. 98, no. 9, pp. 1045-1051, 2008.

[26] B. R. Prusty, P. Chaudhuri, V. K. Chaturvedi, M. Saini, B. P. Mishra, and P. K. Gupta, "Visual detection of Brucella spp. in spiked bovine semen using Loop-Mediated Isothermal Amplification (LAMP) assay," Indian Journal of Microbiology, vol. 56, no. 2, pp. 142-147, 2016.
[27] J. Zhang, J. Zhu, H. Ren et al., "Rapid visual detection of highly pathogenic Streptococcus suis serotype 2 isolates by use of loop-mediated isothermal amplification," Journal of Clinical Microbiology, vol. 51, no. 10, pp. 3250-3256, 2013.

[28] A. B. Nurul Najian, E. A. R. Engku Nur Syafirah, N. Ismail, M. Mohamed, and C. Y. Yean, "Development of multiplex loop mediated isothermal amplification (m-LAMP) label-based gold nanoparticles lateral flow dipstick biosensor for detection of pathogenic Leptospira," Analytica Chimica Acta, vol. 903, pp. 142-148, 2016.

[29] S. Nair, R. Manimekalai, P. Ganga Raj, and V. Hegde, "Loop mediated isothermal amplification (LAMP) assay for detection of coconut root wilt disease and arecanut yellow leaf disease phytoplasma," World Journal of Microbiology and Biotechnology, vol. 32, no. 7, article no. 108, 2016.

[30] C. Zhang, J. Zhu, J. Yang, Y. Wan, T. Ma, and Y. Cui, “Determination of $\mathrm{ABO}$ blood group genotypes using the real-time loop-mediated isothermal amplification method," Molecular Medicine Reports, vol. 12, no. 4, pp. 5963-5966, 2015.

[31] G. Xiao, C. Qin, Z. Wenju, and C. Qin, "Development of a real-time quantitative PCR assay using a TaqMan minor groove binder probe for the detection of $\alpha$-lactalbumin in food," Journal of Dairy Science, vol. 99, no. 3, pp. 1716-1724, 2016.

[32] B. Druml, W. Mayer, M. Cichna-Markl, and R. Hochegger, "Development and validation of a TaqMan real-time PCR assay for the identification and quantification of roe deer (Capreolus capreolus) in food to detect food adulteration," Food Chemistry, vol. 178, pp. 319-326, 2015. 

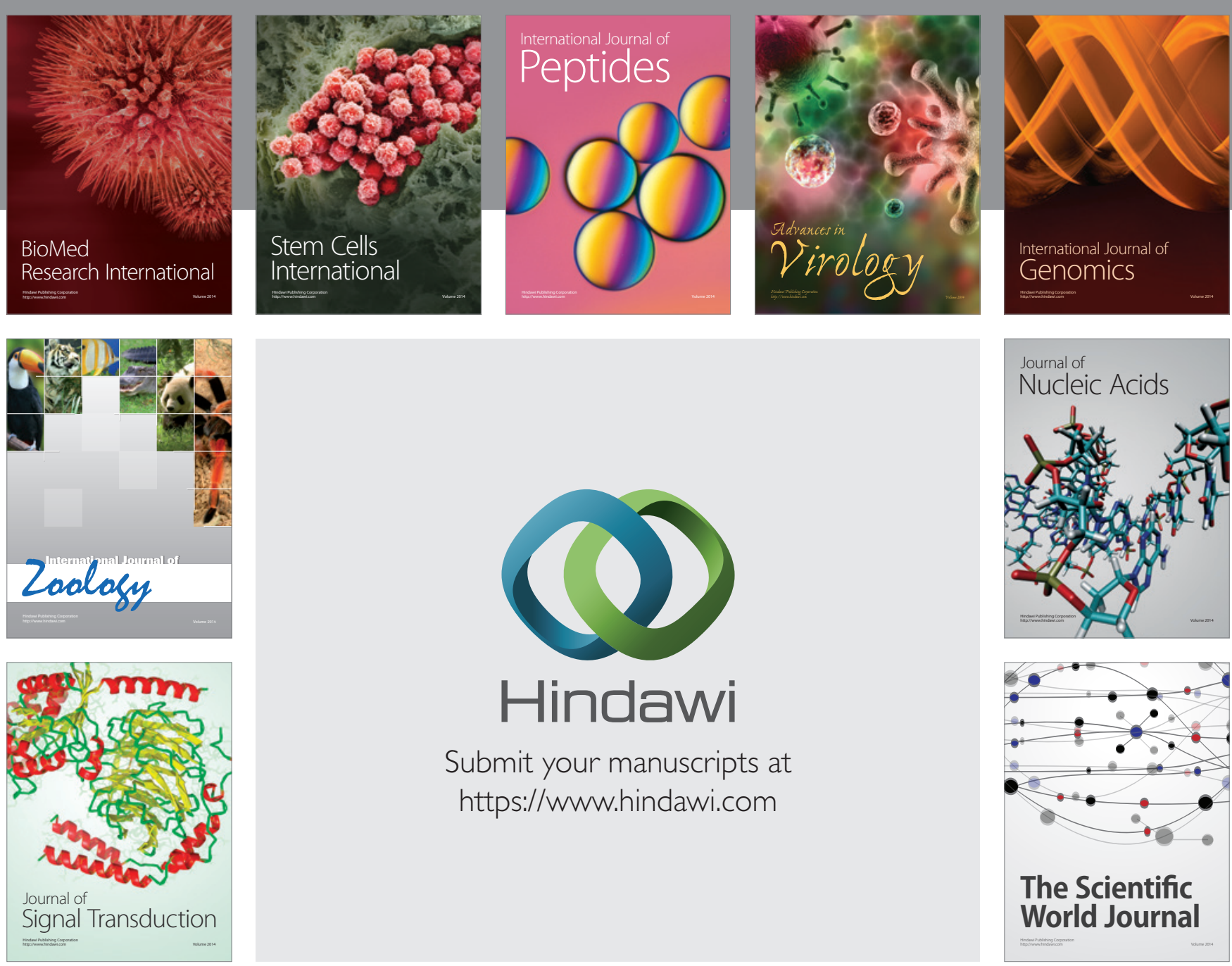

Submit your manuscripts at

https://www.hindawi.com
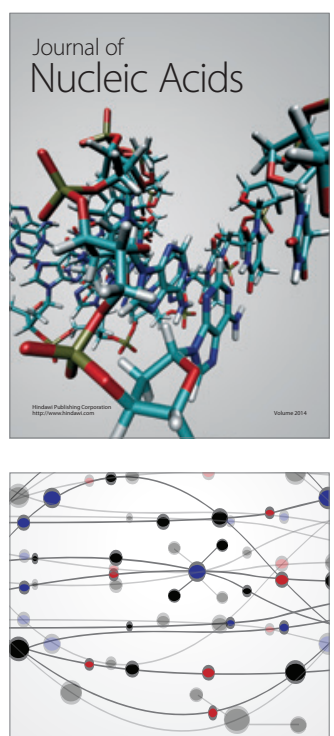

The Scientific World Journal
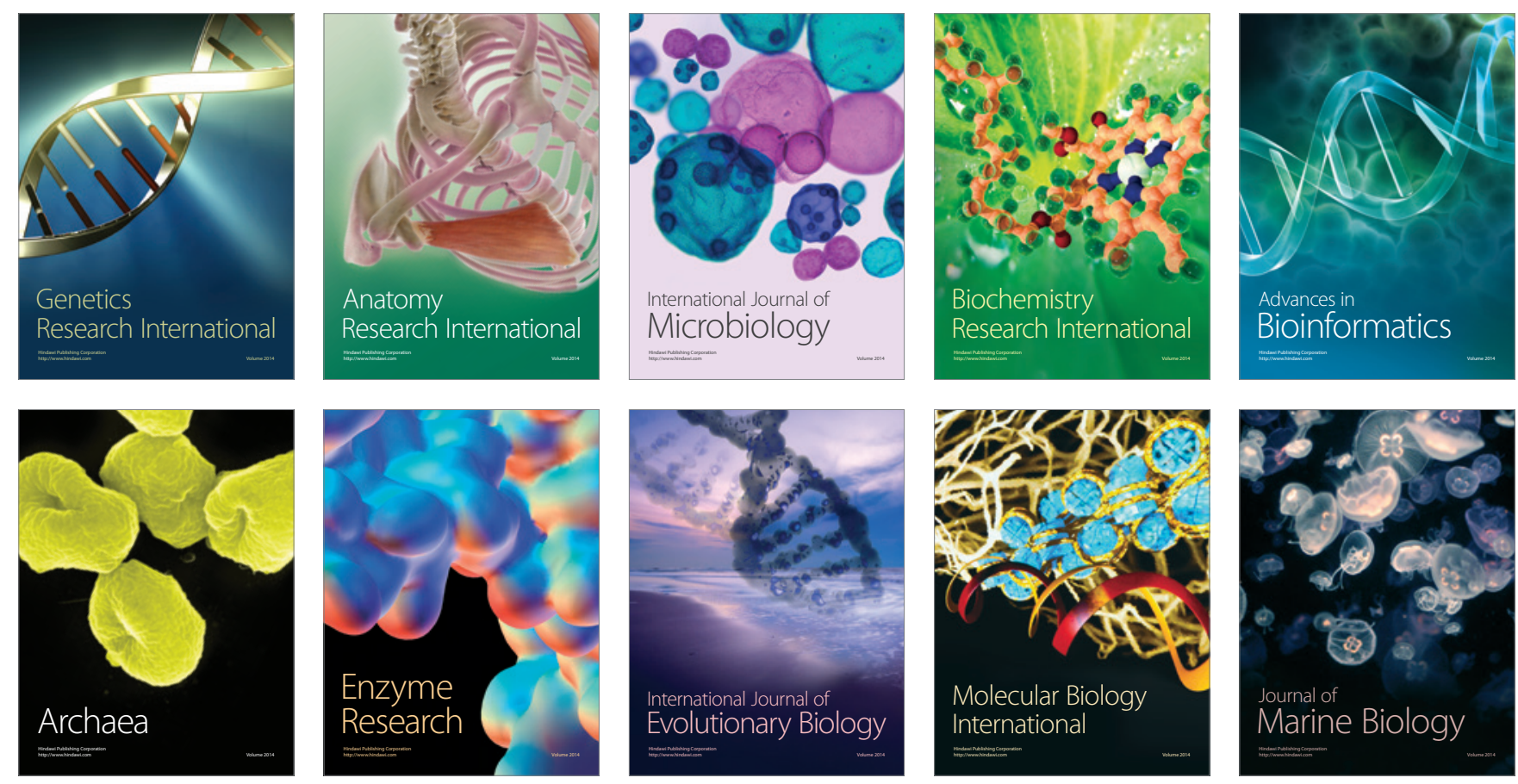